\title{
Methods for Structural Stress Determination according to EN 13445-3 Annex NA - Comparison with other Codes for Unfired Pressure Vessels
}

\author{
Ralf Trieglaff ${ }^{1,{ }^{*}}$, Jürgen Rudolph ${ }^{2}$, Martin Beckert ${ }^{1}$, and Daniel Friers ${ }^{3}$ \\ ${ }^{1}$ TÜV NORD EnSys GmbH \& Co. KG, 22525 Hamburg, Germany \\ ${ }^{2}$ Framatome GmbH, 91052 Erlangen, Germany \\ ${ }^{3}$ Krones AG, 93073 Neutraubling, Germany
}

\begin{abstract}
The European Pressure Vessel Standard EN 13445 provides in its part 3 (Design) a simplified method (Clause 17) and a detailed method for fatigue assessment (Clause 18). Clause 18 "Detailed Assessment of Fatigue Life" is under revision within the framework of the European working group CEN/TC 54/WG 53 Design methods with the aim of reaching a significant increase in user-friendliness and a clear guideline for the application.
\end{abstract}

\begin{abstract}
This paper is focused on the new informative annex NA "Instructions for structural stress oriented finite elements analyses using brick and shell elements". As an essential amendment for the practical user, the determination of structural stress ranges for fatigue assessment of welds is further specified in this new annex. Different application methods for the determination of structural stresses are explained in connection with the requirements for finite element models and analyses.
\end{abstract}

This paper will give a short overview of the proposed approaches of structural stress determination in annex NA of the revised EN 13445-3. It will present the status of the approaches based on the results of fatigue analyses according to EN 13445-3 Clause 18 for different application examples.

For verification purposes, the results of the approaches proposed in EN 13445-3 are compared with the results of other pressure vessel design codes for nuclear and non-nuclear application.

\section{Introduction}

The "Recommendations for fatigue design of welded joints and components" by Professor A. Hobbacher (see [1] to [3]) opened new horizons in the determination of the hot-spot structural stress and the fatigue assessment of welded joints in different engineering disciplines in general. The adoption of the concept of structural stress in the standard EN 13445-3 started as early as in the 1990ies by the work of Professor Stephen Maddox from TWI.

Generally speaking, the European Pressure Vessel Standard EN 13445 provides in its part 3 (Design) a simplified method for fatigue assessment (Clause 17) and a detailed method of fatigue assessment (Clause 18) [4]. Clause 18 "Detailed Assessment of Fatigue Life" is currently under revision within the framework of the European working group CEN/TC 54/WG 53 - Design methods. An extensive overview of the baseline of revision was given in [5]. All amendments primarily aim at a significant increase in user friendliness and clear guidelines for application.
Three items of the revised clause 18 and related annexes are outstanding:

- Detailed guidelines for the fatigue assessment of welded pressure vessel components based on the structural hot-spot stress approach

- Detailed guidelines for the determination of the relevant stresses and stress ranges based on shell type and brick type finite element models

- Detailed guidelines for the cycle counting issue.

The basic rules for unwelded components essentially remain unchanged.

As an essential amendment for the practical user the determination of structural stress ranges for the fatigue assessment of welds is further detailed in the new informative annex NA "Instructions for determining structural hot-spot stress by finite element analysis using shell and brick elements". Here, different applicable methods for the determination of structural stresses are explained in connection with the requirements of the finite element models and analyses.

\footnotetext{
* Corresponding author: rtrieglaff@tuev-nord.de
} 
As mentioned before the concept of structural stress was introduced into Clause 18 "Detailed Assessment of Fatigue Life" of the standard EN $13445-3$ as early as 1990 by Professor Stephen Maddox from TWI. This concept was quite new for pressure vessel designers who usually performed fatigue analysis using fatigue curves based on the tests of smooth, unnotched and polished standard specimens in connection with some weld factor. In 2002, the standard EN 13445-3 was published with rules transposing the results of (component) fatigue tests on welded specimens performed in laboratory. Nevertheless, it paved the way to catch up with overall technical developments of the fatigue design of welds in other engineering fields. Besides fracture mechanics based crack propagation approaches the widely applied methods for the fatigue design of welded structures are (see [1] to [3]):

- Nominal stress approach

- Structural stress approach

- Notch stress approach.

\section{Overview on the revised EN 13445-3, Clause 18 [4]}

The nominal stress approach (e.g. design S-N curves of Eurocode 3 [6] and IIW Guidelines [1]-[3]) constituted the basis of the EN 13445 S-N curves for weld details. The design S-N curves are described by the equivalent stress range $\Delta \sigma$, and the fatigue life in cycles N. C is a constant dependent on the fatigue class and a slope of $\mathrm{m}=3$ was imposed when deriving component design curves up to $5 \cdot 10^{6}$ cycles $\left(\mathrm{m}=5\right.$ up to $1 \cdot 10^{8}$ cycles for variable amplitude loading). The design curves refer to particular weld details, because the stress concentration effect of the weld detail is already included in the S-N curve. The assignment of the welding details to the design curves (fatigue classes) is based on (the equally revised) table 18-4 in [4].

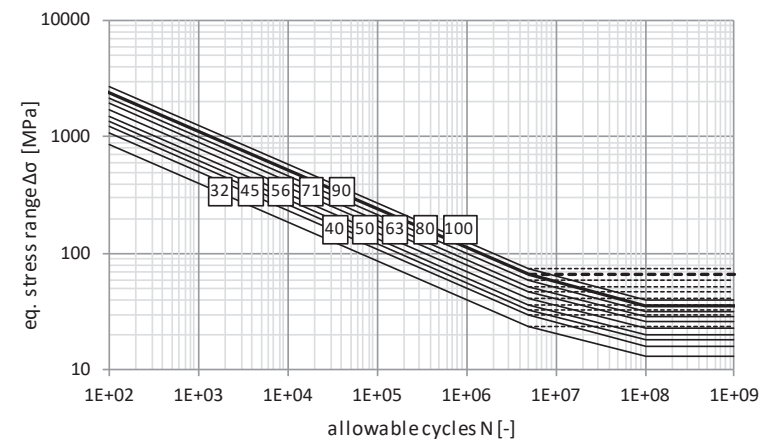

Figure 1: Fatigue design curves for welded components according to [4]

The application of the structural hot spot stress concept in EN 13445-3, Clause 18 [4] was discussed in detail in [5]. Detailed in Annex NA of EN 13445-3 [4] the determination of the structural hot-spot stress can be based on (see Fig. 2):

- Linear extrapolation of the stress on the surface (usually at distances $l_{1}=0.4 \mathrm{e}$ and $1_{1}+l_{2}=1.0 \mathrm{e}$ ) in shell type or brick type finite element models
- Quadratic extrapolation of the stress on the surface usually at distances $1_{1}=0.5 \mathrm{e}$ and $1_{1}+l_{2}=1.5 \mathrm{e}$ and $1_{1}+l_{2}+l_{3}=2.5 \mathrm{e}$ ) in shell type or brick type finite element models

- Linearizing the stresses through the section thickness (path linearization in brick type finite element models)

- Geometric removal of the stress singularity by rounding the weld with an appropriate radius (CAB concept according to [9])

- Use of the stress at a position of $2.5 \mathrm{~mm}$ in front of the weld toe (Haibach concept [10]) usually in brick type finite element models.

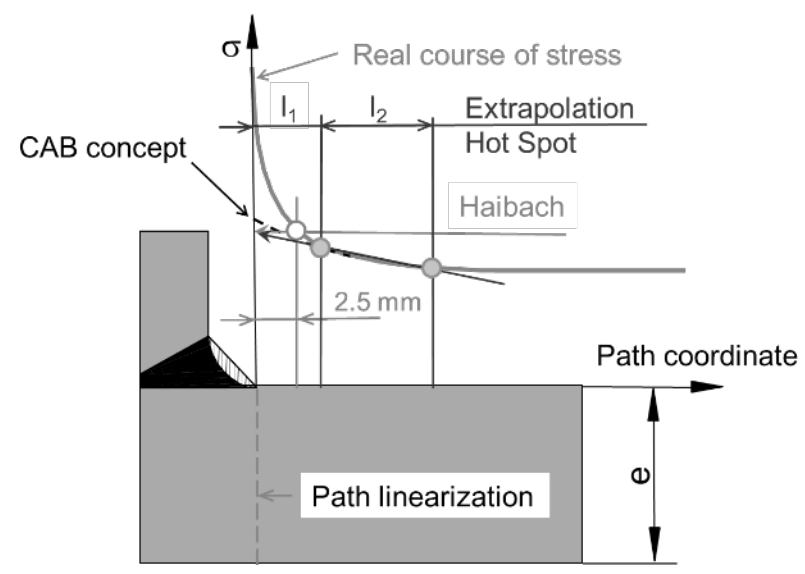

Figure 2: Methods for the determination of the structural hot-spot stress according to [4]

In the case, that the calculated linearized stress range $\Delta \sigma_{\text {eq,mech }}$ exceeds twice the material's yield strength, a correction factor should be applied to account for effects of material plasticity [4]. The following defines this factor $k_{e}$ :

$$
k_{e}=1+A_{0}\left(\frac{\Delta \sigma_{e q, \text { mech }}}{2 R_{p 0.2 T}}-1\right)
$$

The factor $\mathrm{A}_{0}$ depends on the materials tensile strength. For ferritic material with $500 \mathrm{MPa} \leq R_{m} \leq 800 \mathrm{MPa}, A_{0}$ is calculated by the following formula:

$$
A_{0}=0.4+\frac{R_{m}-500 M P a}{3000 M P a}
$$

The corrected stress range is given by the following formula:

$$
\Delta \sigma_{e q}=k_{e} \cdot \Delta \sigma_{e q, \text { mech }}
$$

$k_{\mathrm{e}} \quad$ is the plasticity correction factor for stress due to mechanical loading

$\Delta \sigma_{\text {eq,mech }}$ is the equivalent stress range due to mechanical loading

$\Delta \sigma_{e q} \quad$ is the equivalent stress range with plasticity correction (mechanical and thermal) 


\subsection{General comparison of the fatigue assessment with different codes}

The conceptual basis for the fatigue evaluation of welds is:

- The factorial consideration of the weld seam

- The fatigue assessment based on strain-life fatigue curves (of unnotched and unwelded polished round or hourglass standard specimens)

In fatigue analyses, the fatigue strength reducing influences of weld seams are to be considered as a function of the weld seam treatment. Notice: Stress indices with regard of fatigue are part of the different codes. The background of these Fatigue Strength Reduction Factors (FSRF) are given in WRC 432 [15] and is a base for the codes ASME III/ VIII-2 (US), RCC$\mathrm{M}$ (French) and KTA (German).

Table 1 shows a section of table 8.4-1 of the German Nuclear Code KTA 3201 [16], where several FSRF are given.

Table 1: Examples of FSRF in German Code KTA [16]

\begin{tabular}{|c|c|}
\hline Piping products and joints & $\begin{array}{l}\text { FSRF for pressure } \\
\text { loading }\left(\mathrm{K}_{1}\right)\end{array}$ \\
\hline $\begin{array}{l}\text { Straight pipe, remote from } \\
\text { welds or other discontinuities }\end{array}$ & 1.0 \\
\hline $\begin{array}{l}\text { Butt girth welds between } \\
\text { straight pipes or pipe and butt- } \\
\text { welded item } \\
\text { a) flush } \\
\text { b) as-welded }\end{array}$ & $\begin{array}{l}1.1 \\
1.2\end{array}$ \\
\hline $\begin{array}{l}\text { Longitudinal butt welds in } \\
\text { straight pipe } \\
\text { a) flush } \\
\text { b) as-welded } \mathrm{s}_{\mathrm{c}}>5 \mathrm{~mm} \\
\text { c) as-welded } \mathrm{s}_{\mathrm{c}} \leq 5 \mathrm{~mm}\end{array}$ & $\begin{array}{l}1.1 \\
1.2 \\
2.5\end{array}$ \\
\hline Curved pipe or elbows & 1.0 \\
\hline Branch connections & 2.0 \\
\hline Butt welding tees & 4.0 \\
\hline
\end{tabular}

In the European Code EN 12952-3 [18] for Water-tube boilers and auxiliary installations Fatigue Strength Reduction Factors are given for the categories "mild", "middle" and "strong" depending on the ultimate strength of the material and calculated allowable numbers of cycles.

Table 2: EN 12952-3 - Fatigue strength reduction factors for welds [18]

\begin{tabular}{|l|l|}
\hline $\begin{array}{l}\text { Tensile Strength } \\
R \mathrm{~m}\end{array}$ & $\begin{array}{l}\text { Welding Class } \\
\text { Middle fatigue reduction } \mathrm{K} 2\end{array}$ \\
\hline $\mathrm{MPa}$ & $C_{\mathrm{k} 2}$ \\
\hline 400 & $1.6 \leq 0.21 \lg \mathrm{Na}+0.79 \leq 2.1$ \\
\hline 600 & $1.9 \leq 0.40 \lg \mathrm{Na}+0.60 \leq 3.1$ \\
\hline 800 & $2.1 \leq 0.56 \lg \mathrm{Na}+0.44 \leq 4.0$ \\
\hline 1000 & $2.5 \leq 0.75 \lg \mathrm{Na}+0.25 \leq 5.0$ \\
\hline
\end{tabular}

\subsection{Comparison of the Design Fatigue Curves between the Codes - KTA, ASME III, RCC- $M$, EN 12952-3 and EN 13445-3}

In Figure 3 the design fatigue curves based on unnotched and unwelded polished round or hourglass standard specimens of the codes KTA [16], ASME III [17], RCCM [19] and EN 12952-3 [18] reduced by the FSRF as defined in the codes are shown and compared with the component fatigue design curves as given in EN 13445-3 [4].

Note that this comparison is done under the retention of the different methodological bases as explained above. In the case of the component fatigue curves as given in EN 13445-3 [4] the stress range is proportional to the load of the underlying load controlled tests while in the case of the other mentioned design codes the stress range is plotted in terms of pseudoelastic stress resulting from a simple multiplication of the results of the underlying strain-controlled fatigue tests with Young's modulus and applying a constant FSRF. Comparison results are almost necessarily different, particularly in the high cycle fatigue range $(\mathrm{HCF})$ where the component fatigue curve represents the decrease of the endurance limit due to the weld. Obviously, the application of a constant FSRF is not sufficient to provide the correction for the entire fatigue lifetime range from the low cycle fatigue range (LCF) to the high cycle fatigue range (HCF) and the endurance limit.

Figure 3 displays the comparison of the fatigue curves with middle fatigue strength reduction, in this case the FAT40 of EN 13445 with the factors K3 of EN12952 and FSRF=3.0 of ASME, RCC-M, KTA.

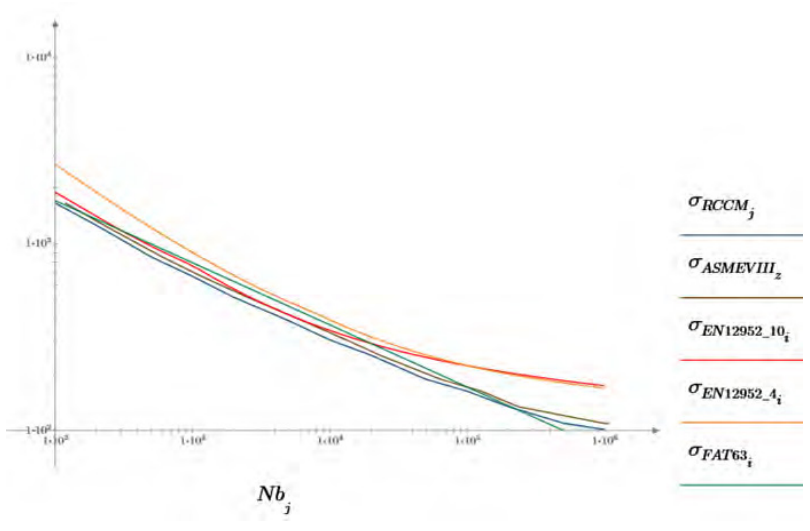

Figure 3: Fatigue curves for middle weld reduction

The comparison shows, that the FAT63-curve is conservative in the high cycle fatigue regime. Below $2 \cdot 10^{5}$ cycles the FAT63-curve should give results above the other curves.

\subsection{Comparison of mechanical correction factors between the Codes - KTA, AD 2000 and EN 13445-3}

The plasticity correction factor for stress due to mechanical loading $k_{e}$ differs between EN 13445-3, AD 2000 [20] and KTA. For a limited material range (given tensile stress and steel alloy type), it is possible to 
compare the correction factors of the different design codes with each other.

The mechanical correction factors $k_{e}$ for the French and American nuclear Code (RCC-M and ASME III) are calculated in a similar way as in the German KTA Code.

Figure 4 displays the correction factor depending on the ratio of mechanical stress range $\Delta \sigma_{\text {eq,mech }}$ and yield stress $R_{p 0.2}$. The curves are only valid for ferritic material with a tensile strength between $500 \mathrm{MPa}$ and $800 \mathrm{MPa}$.

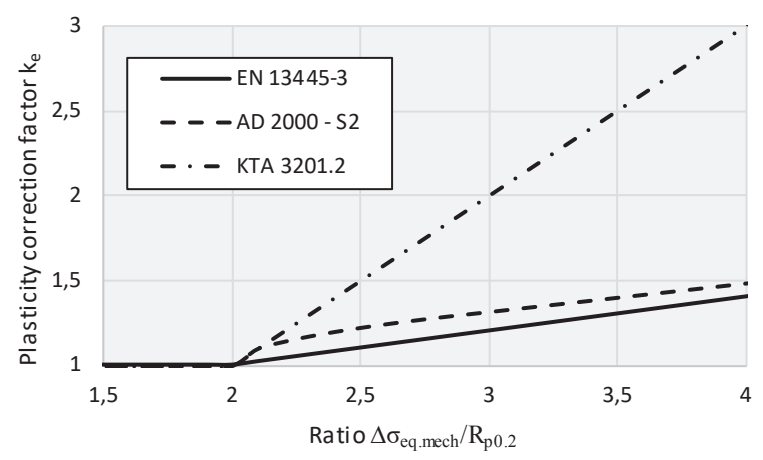

Figure 4: Plasticity correction factor for stress due to mechanical loading

As shown in Figure 4, the correction factor $k_{e}$ need to be taken into consideration only when the mechanical stress range $\Delta \sigma_{e q, \text { mech }}$ exceeds twice the material's yield strength.

The correction factor $k_{e}$ in the nuclear KTA code produces the most conservative values, especially for high stress/strength ratios.

\section{Calculation examples for consolidation of EN 13445-3, clause 18 and annex NA [4]}

\subsection{Specification of Round Robin}

Different calculation examples were analyzed with the target to compare the different proposed approaches of structural stress determination in annex NA of the revised EN 13445-3 based on the results of the fatigue analysis according to Clause 18 of EN 13445-3. It should be noted that two methods for linear and quadratic extrapolation were used for the hot-spot stress approach and the results of volume models with and without modeled welding overlap were compared. Originally, four examples were analyzed for structural stress determination. [14]

The following three calculation examples were analyzed:

(1) Flat head with cylindrical shell

(2) Central nozzle in elliptical head

(3) Nozzle in a cylindrical shell

The calculation example 1, flat head with cylindrical shell, refers to the fatigue tests described in [11]. Figure 5 shows the essential dimensions and cyclic loads for this calculation example 1 .

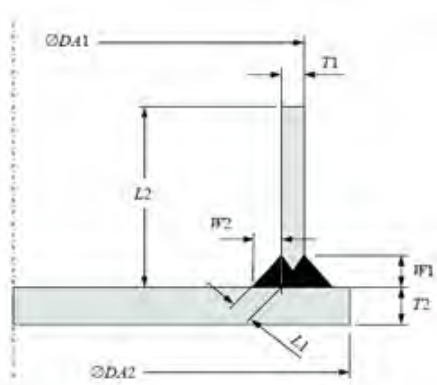

Design Data

$\varnothing \mathrm{DA} 1=508 \mathrm{~mm}$

$\varnothing \mathrm{DA} 2=533,4 \mathrm{~mm}$

$\mathrm{T} 1=4,51 \mathrm{~mm}$

$\mathrm{T} 2=9,73 \mathrm{~mm}$

$\mathrm{L} 1=2,25 \mathrm{~mm}$

$\mathrm{L} 2=200 \mathrm{~mm}$

$\Delta \mathrm{p}=0,414^{*} \mathrm{MPa}$

$\Delta \mathrm{T}=20^{\circ} \mathrm{C}$

Material: SA-516-70

Figure 5: Example 1 - Flat head with cylindrical shell

The calculation example 2, central nozzle in elliptical head, and the calculation example 3, nozzle in a cylindrical shell, based on the document CEN/TC $54 \mathrm{~N}$ 1715 [12], where an application example of EN 13445-3, a vertical vessel with bracket supports, is given. Figure 6 shows the essential dimensions and cyclic loads for example 2 and Figure 7 shows the essential dimensions and cyclic loads for example 3 .

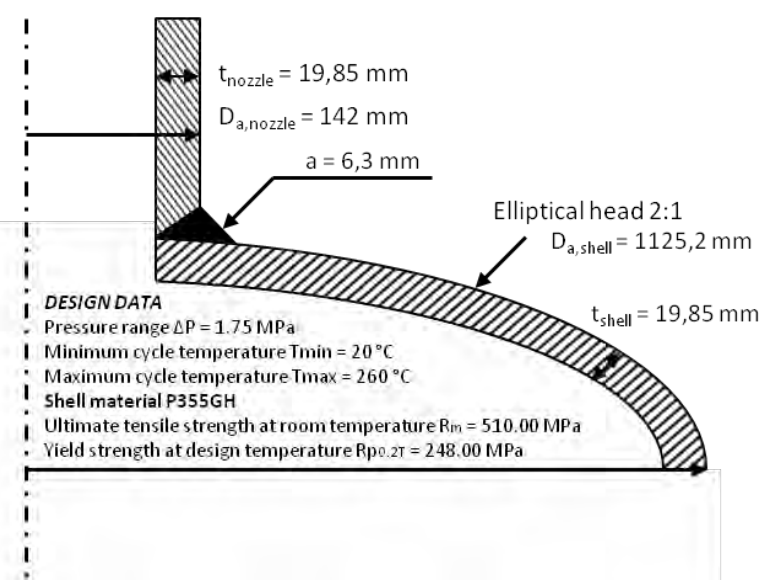

Figure 6: Example 2 - Central nozzle in elliptical head

The calculation examples 1 and 2 could be analyzed based on rotationally symmetrical FEA-models. Therefore, a calculation model has been added so that a $3 \mathrm{D}$ model is also investigated.

The example 3, a nozzle in a cylindrical shell, is based on the proceedings paper no. PVP2013-97568 [13]. Before, the example was used to demonstrate the simplified method for fatigue assessment of the European Pressure Vessel Standard EN 13445. Figure 7 shows the essential dimensions and cyclic loads for this example 3. 


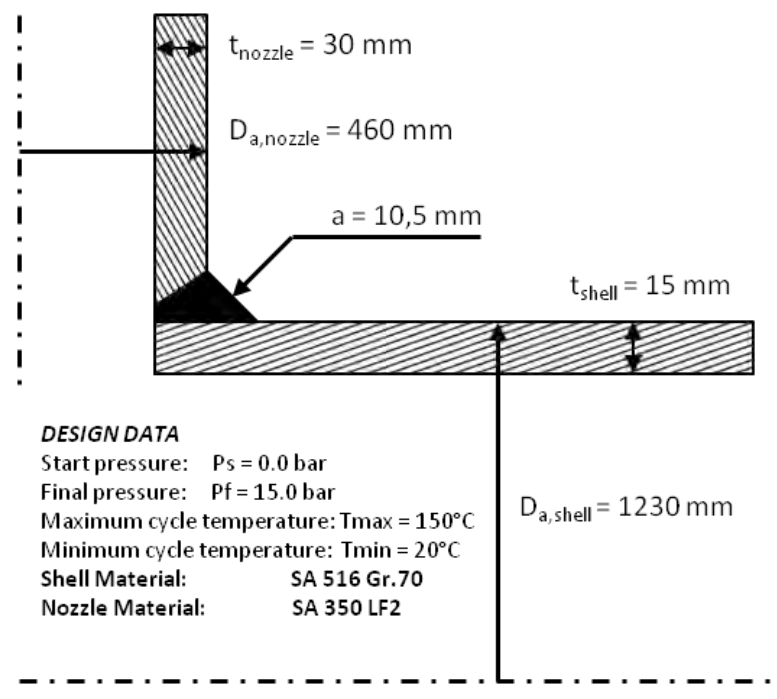

Figure 7: Example 3 - Nozzle in a cylindrical shell

\subsection{Results of Round Robin}

The different methods described in part 2 of the paper were applied by the round robin participants. The stress results are presented on a tabular basis for each example. Further, the resulting allowable load cycles were also analyzed according to EN 13445-3 Chapter 18 and presented in bar graphs.

The extrapolation method (linear and quadratic) uses the stress at the surface of the adjacent structure at different locations. It was not explicitly regulated which locations (distance from hot-spot point) have to be used for the stress extrapolation.

When using shell element formulation, the hot-spot point was defined for all models at the intersection of the shell geometry in the simulation model (equivalent to the midsurface of the components). The fillet weld, which acts as an additional reinforcement of the butt weld, was only considered, when a volumetric (brick) element formulation was used.

The through-wall linearization is presented using different options of calculating the resulting structural stress. The first option (here named equivalent stress method) uses all structural stress components for calculating the equivalent structural stress. The second option uses only the structural stress normal to the hypothetical crack plane, as proposed by ASME VIII-2 [21].
Example 1: Weld at flat end of a cylindrical shell

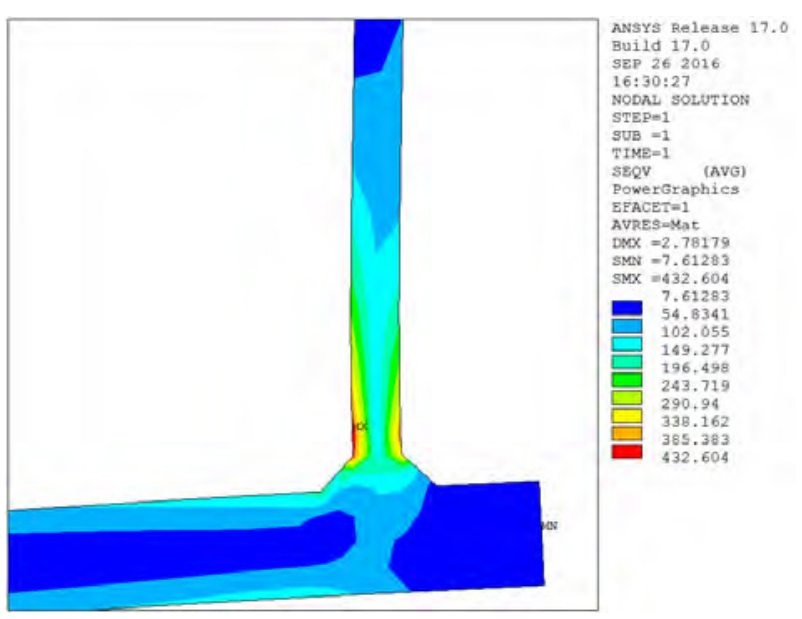

Figure 8: Local stress results (von Mises stress) at the weld of the flat head (with weld reinforcement)

In the Figure 8 above, the equivalent stress results for example 1 are presented. The highest stress occurs at the weld toe inside the vessel, close to the cylindrical shell.

Table 3: Results for different structural stress evaluation concepts

\begin{tabular}{|l|c|c|c|c|}
\hline & $\begin{array}{c}\text { Min. stress } \\
{[\mathrm{MPa}]}\end{array}$ & $\begin{array}{c}\text { Max. Stress } \\
{[\mathrm{MPa}]}\end{array}$ & $\begin{array}{c}\text { Median stress } \\
{[\mathrm{MPa}]}\end{array}$ & $\begin{array}{c}\text { Max. scatter } \\
{[\mathrm{MPa}]}\end{array}$ \\
\hline \multicolumn{5}{|c|}{$\mathrm{FE}$-model with shell element formulation } \\
\hline Direct Method & 434 & 436 & 435 & 2 \\
\hline Linear Extrapolation & 515 & 519 & 517 & 4 \\
\hline Quadratic Extrapolation & 520 & 521 & 521 & 1 \\
\hline Haibach concept (2.5 mm) & - & - & 477 & - \\
\hline \multicolumn{5}{|c|}{ FE-model with volumetric element formulation } \\
\hline Linear Extrapolation & 450 & 452 & 451 & 2 \\
\hline Quadratic Extrapolation & 446 & 453 & 450 & 7 \\
\hline $\begin{array}{l}\text { Linearization } \\
\text { equivalent stress method }\end{array}$ & 311 & 353 & 332 & 42 \\
\hline $\begin{array}{l}\text { Linearization } \\
\text { normal stress method }\end{array}$ & 488 & 496 & 492 & 8 \\
\hline Haibach concept (2.5 mm) & 409 & 410 & 410 & 1 \\
\hline CAB concept & 495 & 496 & 496 & 1 \\
\hline
\end{tabular}

Table 3 shows that there is less scatter between the participants of the working group for all concepts except for the linearization using the equivalent stress method. The structural stress for this method is also very low compared to the other concepts.

Furthermore, there are only small differences between linear and quadratic extrapolation methods in the case of using shell or volumetric elements. In addition to that, various extrapolation schemes have been applied. The different distances $0.5 \mathrm{e} / 1.5 \mathrm{e}$ or $0.5 \mathrm{e} / 1.5 \mathrm{e} / 2.5 \mathrm{e}$ and $0.4 \mathrm{e} / 1.0 \mathrm{e}$ or $0.4 \mathrm{e} / 0.9 \mathrm{e} / 1.4 \mathrm{e}$ to the hotspot for deriving stresses have minor influence on the stress results. 


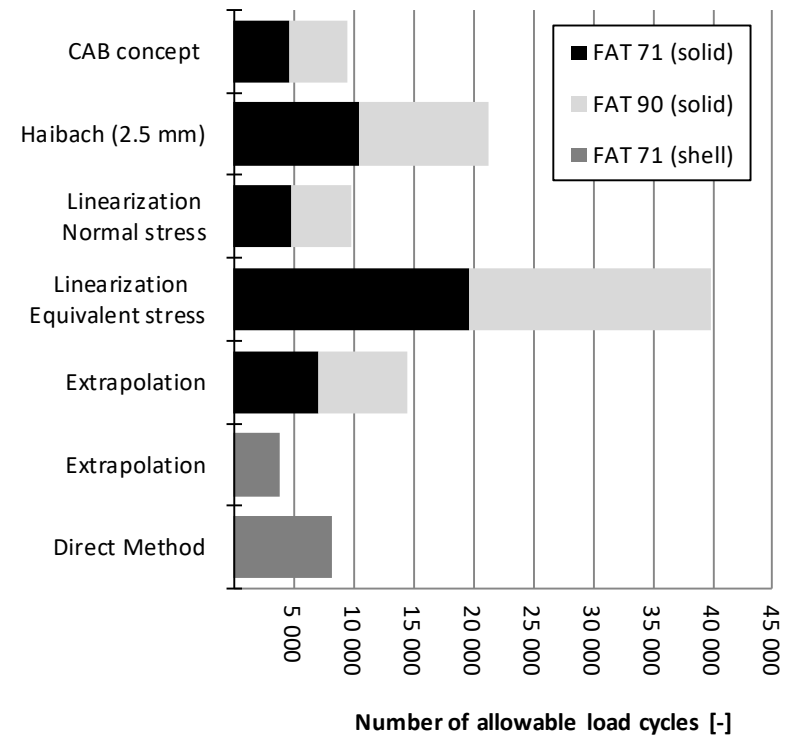

Figure 9: Comparison of allowable load cycles

It should be noted that in the bar graphs the average stress value of the linear and quadratic extrapolation using the same hotspot has been considered in the calculation of the allowable load cycles. The analogous procedure has been executed for volumetric elements.

It can be seen that the equivalent stress method estimates a significantly higher service life than the other methods because of the low stress result. The Haibach method produces a slightly higher number of allowable cycles than for example the linearization (equivalent stress method and normal stress method) or the CAB-concept. Using FAT 71 for shell and solid elements produces comparable results.

\section{Example 2: Nozzle weld in an elliptical head}

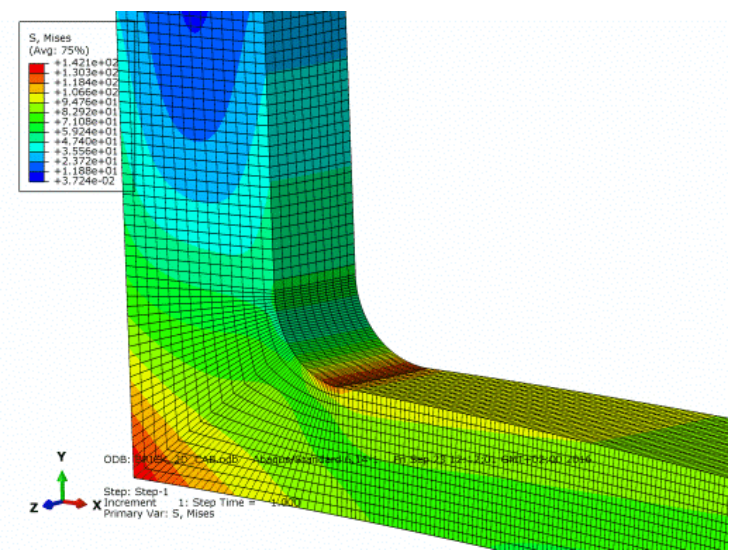

Figure 10: Local equivalent stress results (von Mises) at the nozzle weld (model for CAB-concept)
Table 4: Results for different structural stress evaluation concepts

\begin{tabular}{|l|c|c|c|c|}
\hline & $\begin{array}{c}\text { Min. stress } \\
{[\mathrm{MPa}]}\end{array}$ & $\begin{array}{c}\text { Max. Stress } \\
{[\mathrm{MPa}]}\end{array}$ & $\begin{array}{c}\text { Median stress } \\
{[\mathrm{MPa}]}\end{array}$ & $\begin{array}{c}\text { Max. scatter } \\
{[\mathrm{MPa}]}\end{array}$ \\
\hline \multicolumn{5}{|c|}{ FE-model with shell element formulation } \\
\hline Direct Method & 100 & 101 & 101 & 1 \\
\hline Linear Extrapolation & 101 & 108 & 105 & 7 \\
\hline Quadratic Extrapolation & 102 & 109 & 106 & 7 \\
\hline Haibach concept (2.5 mm) & - & - & 100 & - \\
\hline \multicolumn{4}{|c|}{ FE-model with volumetric element formulation } \\
\hline Linear Extrapolation & 105 & 113 & 109 & 8 \\
\hline Quadratic Extrapolation & 105 & 113 & 109 & 8 \\
\hline $\begin{array}{l}\text { Linearization } \\
\text { equivalent stress method }\end{array}$ & 66 & 99 & 83 & 33 \\
\hline $\begin{array}{l}\text { Linearization } \\
\text { normal stress method }\end{array}$ & 108 & 110 & 109 & 2 \\
\hline Haibach concept (2.5 mm) & 107 & 108 & 108 & 1 \\
\hline CAB concept & 115 & 118 & 117 & 3 \\
\hline
\end{tabular}

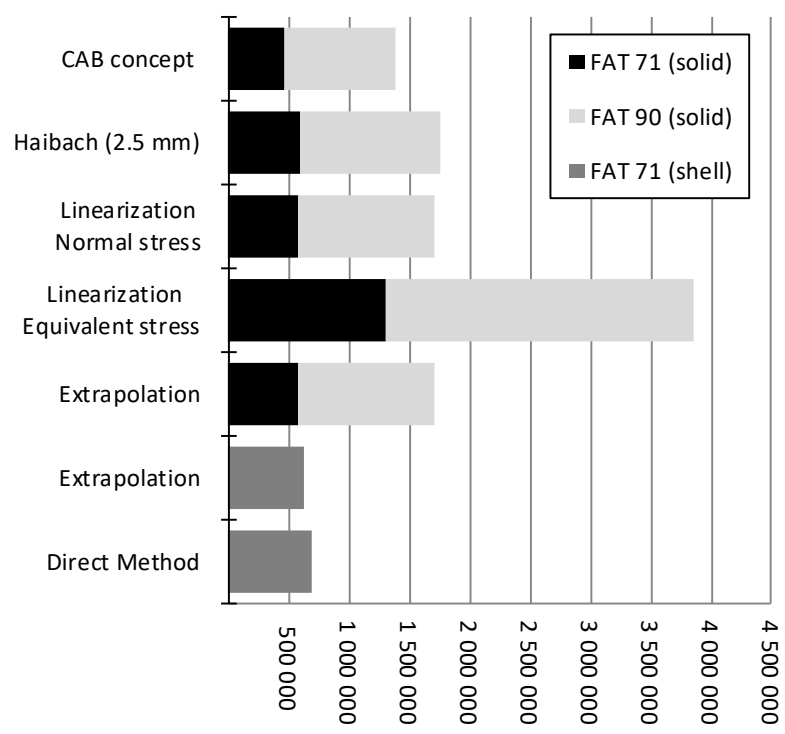

Number of allowable load cycles [-]

Figure 11: Comparison of allowable load cycles

Regarding the scatter of the methods, the same behavior of the methods as in example 1 can be observed. In this example the observed discrepancies in stress results by choosing different hotspots for shell models is less pronounced than in example 1. Again, the equivalent stress method of the linearization estimates more than double the number of load cycles than all other structural stress methods. The $\mathrm{CAB}$ concept is more conservative compared to all other methods using volumetric elements. The Haibach method without the modeled weld reinforcement delivers nearly the same number of allowable load cycles compared to a model with weld reinforcement.

It should be noted that in the bar graphs the average stress value of the linear and quadratic extrapolation using the same hotspot has been considered in the calculation of the service lives. The analogous procedure has been executed for solid elements.

The use of FAT 71 in connection with volumetric elements would result in a comparable number of load cycles for shell models and contribute to the expectation as stated in example 1 (see Fig. 11). 


\section{Example 3: Nozzle weld in a cylindrical shell}

The FE-model for the nozzle weld in a cylindrical shell is the only example using a 3D modeling space instead of an axisymmetric model.

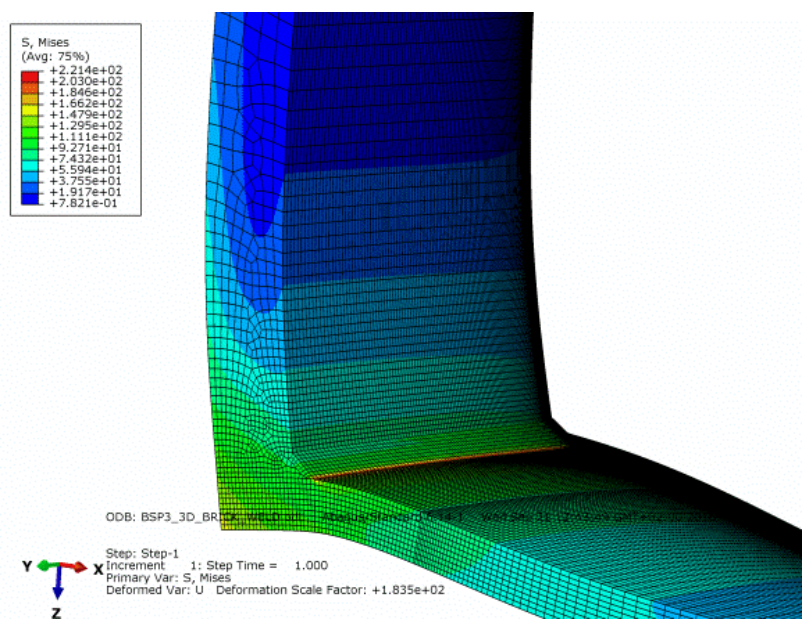

Figure 12: Local equivalent stress results (von Mises) and deformation around the nozzle weld (with modeled weld)

In Fig. 12 the deformation, mesh density and equivalent stress (von Mises) are illustrated. The highest stress level occurs as expected at the weld toe.

Table 5: Structural stress results for the nozzle weld

\begin{tabular}{|l|c|c|c|c|}
\hline & $\begin{array}{c}\text { Min. stress } \\
{[\mathrm{MPa}]}\end{array}$ & $\begin{array}{c}\text { Max. stress } \\
{[\mathrm{MPa}]}\end{array}$ & $\begin{array}{c}\text { Median stress } \\
{[\mathrm{MPa}]}\end{array}$ & $\begin{array}{c}\text { Max. scatter } \\
{[\mathrm{MPa}]}\end{array}$ \\
\hline \multicolumn{5}{|c|}{ FE-model with shell element formulation } \\
\hline Direct Method & - & - & 145 & - \\
\hline Linear Extrapolation & 176 & 177 & 177 & 1 \\
\hline Quadratic Extrapolation & 178 & 178 & 178 & 0 \\
\hline \multicolumn{5}{|}{ FE-model with volumetric element formulation } \\
\hline Linear Extrapolation & 137 & 138 & 138 & 1 \\
\hline Quadratic Extrapolation & 137 & 139 & 138 & 2 \\
\hline $\begin{array}{l}\text { Linearization } \\
\text { equivalent stress method }\end{array}$ & 126 & 128 & 127 & 2 \\
\hline $\begin{array}{l}\text { Linearization } \\
\text { normal stress method }\end{array}$ & 131 & 134 & 131 & 3 \\
\hline Haibach concept (2.5 mm) & 143 & 144 & 144 & 1 \\
\hline CAB concept & 158 & 159 & 159 & 1 \\
\hline
\end{tabular}

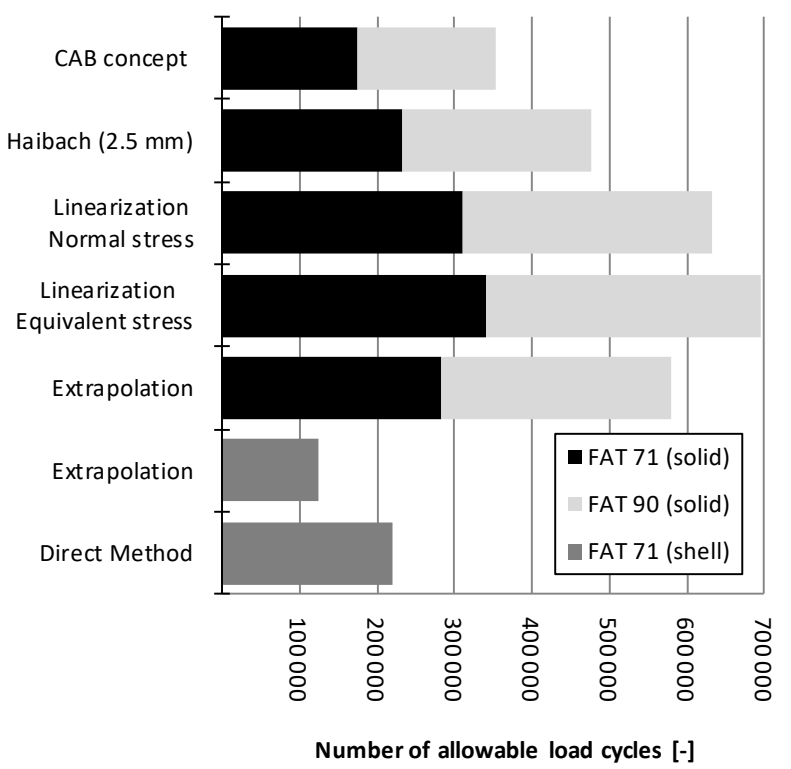

Figure 13: Comparison of the number of allowable load cycles for FAT-71 and FAT-90
The results in Table 5 show very little scatter for all methods used. Even for the through-wall linearization (equivalent stress method), the results are in-line with the other methods.

Remarkable is also the significant difference when using shell or volumetric element formulation.

As the level of stress is lower, when using a volumetric element formulation, the number of allowable load cycles differs a lot between shell and volumetric element formulation.

\subsection{Comparison of the allowable cycles with different design codes}

For comparison of the calculated allowable number of cycles with different design codes, the results of the volumetric FE-models were used. The structural stresses were estimated based on the quadratic extrapolation method. For the assessment procedure of the codes ASME III, ASME VIII-2 [21], RCC-M and KTA, the results of the $\mathrm{CAB}$ concept were used as notch stresses.

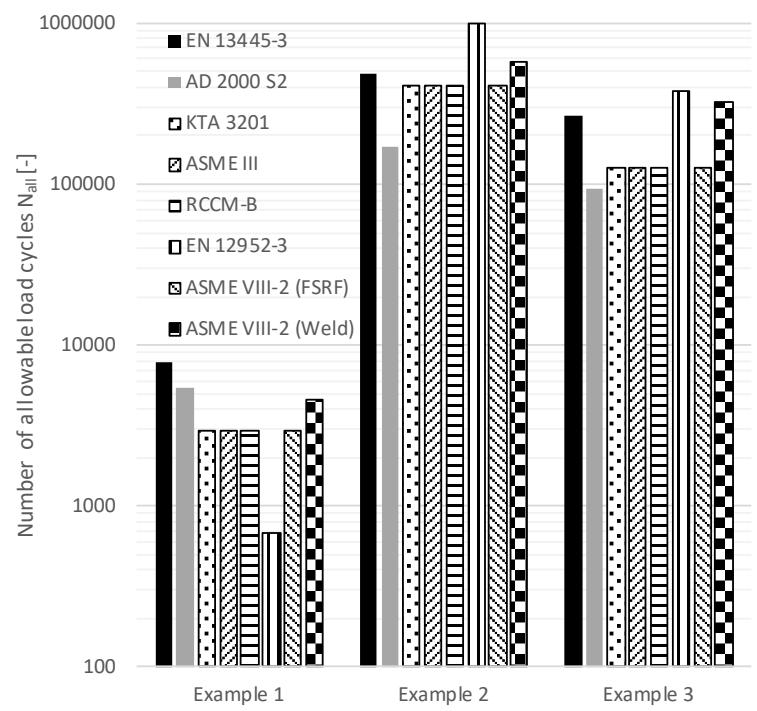

Figure 14: Allowable load cycles for the analyzed examples as a comparison between different codes

The comparison of the results show no fundamental deviations to the other assessment procedures. The results of the weld assessment concept in ASME VIII-2 [21] are close the results in EN 13445-3. The results of EN 12952-3 seems to be conservative in the LCF-region and non-conservative in the HCF-region.

The results according to AD 2000 are comparatively low for example 2 and 3 , because of the classification of the weld geometry in class K2. For example 1, the weld detail was classified in class K1. For the analysis according to EN 13445, all weld details were classified in FAT71.

\section{Summary and Conclusions}

In the following, the results for the calculation examples with regard to the concepts for the determination of the 
structural stresses are evaluated and recommendations are derived.

\section{Hot-spot approach}

The quadratic extrapolation procedure delivers only slightly higher stress values compared to the linear extrapolation. The different methods based on different distances between the surface stress extrapolation points have only negligible influence on the stress result. The use of shell elements instead of brick elements leads in general to higher stress values.

If the fatigue evaluation is based on the weld design fatigue curve FAT90 in general instead of the recommended FAT Class in table 18.4 of EN 13445-3 [4] for brick elements, larger differences for the number of allowable cycles between shell and brick elements will result. As a results, the only use of the FAT Class acc. to 18.4 of EN 13445-3 [4] is proposed.

\section{Through-wall linearization}

The results for all calculation examples show the lowest stress level compared to all other concepts when using the equivalent linearized stresses. In addition, the deviation between the results of the participants of the Round robin is the biggest. This appears to be due to the mesh dependency of the results. Therefore, a modification of this method was investigated. The modification uses the largest stress perpendicular to the expected crack plane, as proposed by ASME VIII-2 [21]. For the three calculation examples, the modification shows different success. Further investigations are necessary.

\section{Haibach-concept}

The calculated structural stresses of the Haibach-concept for the calculation examples 2 and 3 are in the same level as the Hot-spot-approach. For the example 1, this concept underestimated the structural stress. The reason is the thin shell thickness of $4.51 \mathrm{~mm}$ compared with the evaluation distance of $2.5 \mathrm{~mm}$ from the weld toe, where the stress has to be taken. For thin-walled structures, the result may be non-conservative. Therefore, a different method is proposed in the preliminary annex NA of EN 13445 [4]. The Haibach stress is located at $2.0 \mathrm{~mm}$ from the weld toe and for a smaller wall thickness than $8 \mathrm{~mm}$, the stress is taken from the point $0,25^{*}$ wall thickness.

\section{CAB-concept}

The calculated structural stresses of the CAB-concept have a higher stress level than all other methods for all calculation examples. This concept shows for all applications stable results regardless of different grid sizes in the FE-models of the participants of the round robin test. For mechanical loads, full penetration welds and testing group 1 or 2 , the stresses estimated by the CA-concept can be reduced by a correction factor of $\mathrm{f}_{\mathrm{CAB}}=0.95[4]$.

The comparison with other codes in section 3.3 of the paper shows, that the proposed calculation procedure in
EN 13445-3 lead to results closed to the results of other well-established codes. 


\section{References}

[1] Hobbacher, A.: Recommendations for fatigue design of welded joints and components. IIW document IIW-1823-07 ex XII-2151r4-07/XV1254r4-07, 2008.

[2] Hobbacher, A.: Recommendations for Fatigue Design of welded joints and components. International Institute of Welding document IIW document IIW-1823-07. Welding Research Council Bulletin 520, New York (2009)

[3] Hobbacher, A.: Recommendations for Fatigue Design of Welded Joints and Components. Second Edition. IIW document IIW-2259-15 ex XIII-2460-13/XV-1440-13, revision of XIII2151r4-07/XV-1254r4-07, Springer Cham Heidelberg New York Dordrecht London, 2016

[4] CEN/TC 54; EN 13445-3:2014/prA3:2015; 201510.

Clause 18: „Detailed assessment of fatigue life“ Annex NA: "Instructions for determining structural hot-spot stress by finite element analysis using shell and brick elements "

Annex NB: , Cycle counting and determination of equivalent stress range"

[5] Rudolph, J.; Baylac, G.; Wilhelm, P.; Wintle, J.; Buennagel, E.: Recent Amendments of EN 13445-3, Clause 18 and Related Annexes: Detailed Assessment of Fatigue Life. Proceedings of PVP2014. Paper No. PVP2014-28129. ASME Pressure Vessels \& Piping Conference. July 20-24, 2014, Anaheim, California, USA

[6] Eurocode 3 - Design of steel structures - prEN 1993.

European Committee for Standardization, Brussels, 1992

[7] Maddox, S. J.: Key developments in the fatigue design of welded constructions.

2003 IIW Portvin Lecture, Proc. IIW Int. Conf. on „Welded Construction for Urban Infrastructure“, ISIM, Timisoara, Romania, 2003.

[8] Niemi, E.; Fricke, W.; Maddox, S. J.: Fatigue Analysis of welded Components - Designer's guide to the structural hot-spot stress approach. IIW-1430-00, first published 2006, reprinted 2011

[9] J. Rudolph, M. Rauth, E. Weiß: Modellgebundener Strukturspannungsnachweis für zyklisch beanspruchte Zylinder-Stutzen-Verbindungen ohne Schweißnahtnachbearbeitung.

TU-Zeitschrift 43 (2002), No. 6, pp. 19/26

[10] Haibach, E.: Die Schwingfestigkeit von Schweißverbindungen aus der Sicht einer örtlichen Beanspruchungsmessung. (The fatigue strength of welded joints considered based on local stress measurement).

LBF Report FB77, Fraunhofer-Inst. für

Betriebsfestigkeit Darmstadt Germany (1968)
[11] Hinnant, C.: Fatigue Testing and Life Estimates of Welded Flat Head Pressure Vessel Joints.

Proceedings of PVP2006. Paper No. PVP200693967. ASME Pressure Vessels \& Piping Conference July 23-27, 2006, Vancouver, BC, Canada

[12] Document CEN/TC 54 N 1715: Example of Application of EN 13445 - Vertical Vessel with Bracket Supports (Cen/Tr 13445-102), 10 February 2014

[13] Lidonnici, F.: The Simplified Method for Fatigue Assessment of the European Pressure Vessel Standard EN 13445, Proceedings of PVP2013. Paper No. PVP2013-97568, ASME Pressure Vessels \& Piping Conference July 14-18, 2013, Paris, France

[14] Trieglaff, R.; Rudolph, J.; Beckert, M.; Hauser, F.: Comparison of Methods for Structural Stress Determination according to EN13445-3 Annex NA Proceedings of PVP2017. Paper No. PVP201766112. ASME Pressure Vessels \& Piping Conference. July 16-20, 2017, Hawaii, USA

[15] Welding Research Council (WRC) bulletin 432 Fatigue strength reduction and stress concentration factors for welds in pressure vessels and piping, June 1998

[16] KTA Program of Standards, Standard No. 3201.2, Components of the Reactor Coolant Pressure Boundary of Light Water Reactors, Part 2: Design and Analysis, Issue November 2013

[17] ASME Boiler and Pressure Vessel Code Section III, Rules for Construction of Nuclear Facility Components, Div. 1 The American Society of Mechanical Engineers, New York, 2017 edition

[18] EN 12952-3Water-tube boilers and auxiliary installations - Part 3: Design and calculation for pressure parts of the boiler; German version EN 12952-3:2011

[19] RCC-M, Design and Construction Rules for Mechanical Components of PWR Nuclear Islands, afcen, 2012 edition

[20] AD 2000 Merkblatt S2 Analysis for cyclic loading German version TÜVIS Prüfgrundlagen, Edition 07.2012

[21] ASME Boiler and Pressure Vessel Code Section VIII-2, Rules for Construction of Pressure Vessels Division 2 - Alternative Rules The American Society of Mechanical Engineers, New York, 2017 edition 